\title{
Results on Ultra-Precise Magnet Yoke Sectors Assembly Tests
}

\author{
M. Modena, R. Leuxe, and M. Struik
}

\begin{abstract}
Due to beam dynamics requirements and to reduce the cost and power consumption for the next generation of particle accelerators, their magnet systems need to be more and more compact and precise. As a consequence, the required tolerances on machining and assembling of components like the electromagnet iron yoke sectors are becoming tighter. $R \& D$ and prototypes procurement for future projects like the Compact Linear Collider require quadrupole yoke quadrants machined with micrometric precision, and assembled with an overall precision in the range of $\pm 10 \mu \mathrm{m}$. A test program was launched at CERN in order to investigate the feasibility of such tight assembly tolerances. The program consists in testing three different types of assembly methods for ultra-precise dummy quadrants produced by electro discharge machining. The aim is to identify the best performing assembly procedures for magnet iron yokes. In this paper the first relevant results of this test program are presented and discussed.
\end{abstract}

Index Terms-Assembly, colliding beam accelerators, electromagnets, precision engineering.

\section{INTRODUCTION}

$\mathbf{T}$ HE COMPACT Linear Collider (CLIC) is an electronpositron linear collider project providing a maximum center-of-mass energy of $3 \mathrm{TeV}$ with a high accelerating gradient in the range of $100 \mathrm{MV} / \mathrm{m} \mathrm{[1]}$. The backbone of the magnetic structure of the $\mathrm{e}^{+} / \mathrm{e}^{-}$linacs consists of more than 4000 very compact normal conducting Main Beam Quadrupoles (MBQ) with an inner bore diameter of $10 \mathrm{~mm}$ providing a nominal gradient of $200 \mathrm{~T} / \mathrm{m}$. The solid magnet yoke quadrants are made of 1010 grade steel. In order to guarantee the necessary magnetic field quality, overall machining and assembly tolerances in the range of $\pm 10 \mu \mathrm{m}$ are required. Methods to obtain such accurate assemblies are derived from high precision mechanical engineering practice and the quadrants are normally located by very precise dowel pins or keys. Other methods include the use of stainless steel rings fixed to the poles at the magnet extremities or the use of calibrated spacers between the poles [2], [3]. Due to the anticipated high number of magnets to be produced, simple, cheap and rapid assembly solutions are needed. In order to investigate these aspects, a specific test program was launched at CERN in 2012 for the manufacture of a yoke mock-up to assess different assembly methods. The main aim was to analyze the precision achievable within the methods tested and to identify the most competitive method in terms of

Manuscript received July 13, 2013; accepted October 25, 2013. Date of publication November 5, 2013; date of current version December 3, 2013.

The authors are with the CERN, 1211-Geneva, Switzerland (e-mail: michele. modena@cern.ch).

Color versions of one or more of the figures in this paper are available online at http://ieeexplore.ieee.org.

Digital Object Identifier 10.1109/TASC.2013.2288422

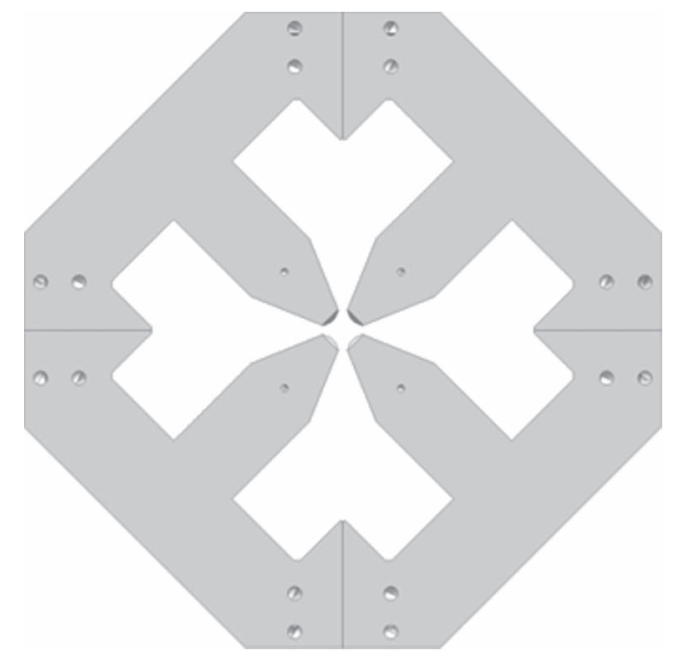

Fig. 1. Cross section of a CLIC MBQ quadrupole yoke.

quadrants machining cost and time. A secondary aim of this program was to verify the capability and accuracy of a new electro discharge machining (EDM) stand recently purchased by the CERN Main Workshop.

\section{The Real MbQ Yoke and the Test Pieces Design}

Fig. 1 shows a cross-section of the real MBQ yoke assembly (magnet aperture diameter: $10 \mathrm{~mm}$, maximum height and width: $232 \mathrm{~mm}$ ) as extracted from the manufacturing drawings [4]. Depending on the MBQ version (Type 1 to Type 4) the yoke lengths can vary from $332 \mathrm{~mm}$ to $1827 \mathrm{~mm}$. As concerning the impact on the magnetic field quality, the most critical surfaces are the pole profiles. The mating surfaces between quadrants (two orthogonal plane surfaces per quadrant) are also critical since they strongly influence the final quadrupolar shape, fundamental in achieving the required magnetic field quality.

Figs. 2 and 3 show the dummy test quadrants manufactured for this test program; two different mock-up pieces were produced (identified in the figures by the different colors). Crosssectional main dimensions are similar to the real quadrupole yoke, with maximum height and width $232 \mathrm{~mm}$. Axial length is $67 \mathrm{~mm}$ and aperture $10 \mathrm{~mm}$ but in the case of the test quadrants the inner bore surfaces are circular arcs, this shape is easier to machine and easier to measure precisely on a $3 \mathrm{D}$ measuring machine, while in the real magnets (Fig. 1) the poles are machined with the conventional convex hyperbolic shape. The difference between the two types of dummy test quadrants are at the level of the mating surfaces of each quadrant which 


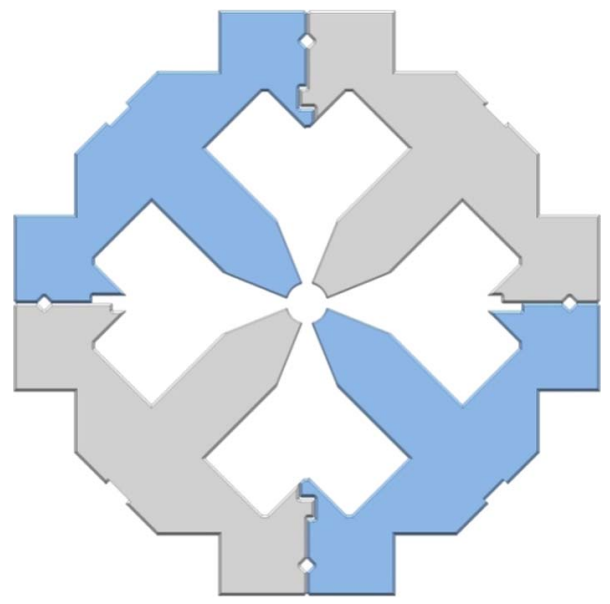

Fig. 2. Cross section of the dummy test quadrants. Configuration 1-with: "straight plane" assembly method and/or "V-grooves with pins" for the horizontal and vertical mating surfaces.

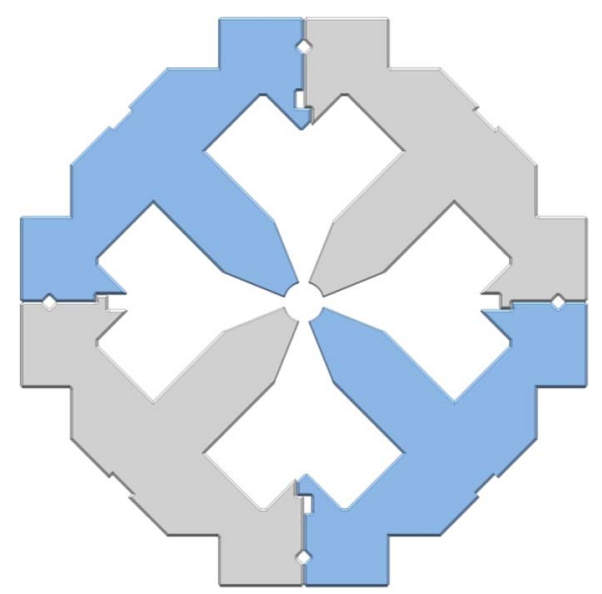

Fig. 3. Cross section of the dummy test quadrants. Configuration 2-with: "assembly with step" assembly method for all four mating surfaces.

are not identical and this variation enables, by rotation of the pieces, two different possible assembly configurations.

In Fig. 2 ("Configuration 1") the contact between horizontal and vertical mating surfaces is of type a): "straight plane" or of type b): "V-grooves with pins".

In Fig. 3 ("Configuration 2"), for all the four mating surfaces the contact between quadrants is assured by contact type c): "assembly by steps".

The final precision of the yoke assembly depends on the intrinsic machining quality of each quadrant and on the chosen assembly method, the degrees of freedom during the assembly phase being different for the two configurations.

\section{Manufacture of the Test Quadrants}

Electro discharge machining (EDM) was chosen for the production of the test pieces. The nominal resolution of the EDM Machine (AGIE CHARMILLES FI 640 CCS in the CERN Main Workshop) is $0.05 \mu \mathrm{m}$. This very high resolution is declared for machining along a single axis. Considering the movement precision along the other axes, the vibration of the wire, the behavior of the material being cut and the influence

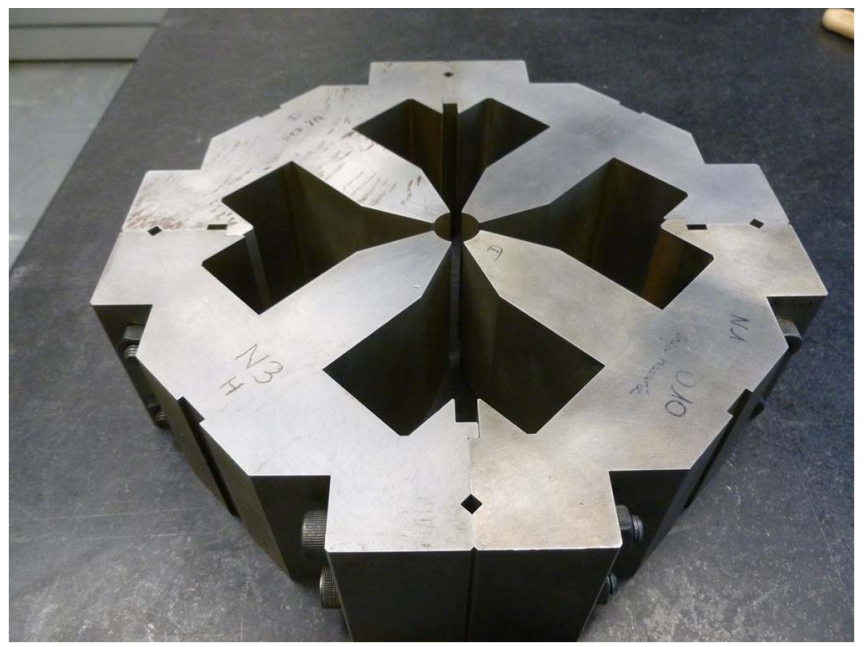

Fig. 4. Manufactured test pieces (by EDM) in a configuration 2 layout.

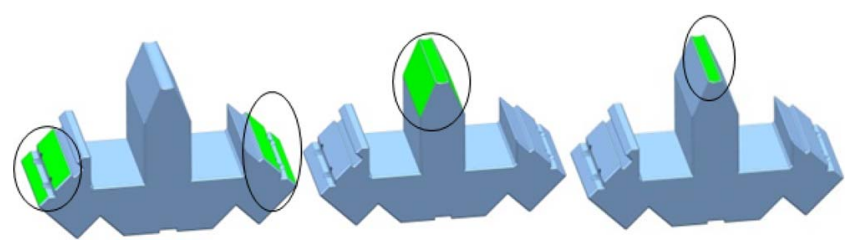

Fig. 5. Individually measured regions to check the machining precision and tolerances are: on the left the mating surfaces (reference planes A and B); on the center the pole profile region; on the right the pole cylindrical part.

of all other manufacturing parameters (the EDM machine was still in a commissioning phase) the target for the test (defined as global surface profile tolerance according to ASME Y14.52009 for the most critical surfaces) was set to $10 \mu \mathrm{m}$. Machining to the final shape is done in several approximating steps. Stress relieving between machining steps was considered not necessary. Fig. 4 shows the manufactured pieces (here assembled in a "Configuration 2" layout. The "snap fit" joint of the mating surface is visible as are 3 of the 4 pairs of inter-connecting bolts.

A FERRANTI Merlin 750 3D measuring machine was used for the metrology check of the manufactured pieces inside the thermally controlled area of the CERN Metrology Laboratory. Each piece was measured at 7 different cross-sections along its longitudinal dimension.

The individual shape tolerances obtained (see also Fig. 5) to be compared with the $10 \mu \mathrm{m}$ target envelope are:

a) Planarity of the mating surfaces of each test piece (reference planes A and B):

$$
\begin{aligned}
& \text { Piece } \mathrm{N} 1=9 \mu \mathrm{m} \text { for } \mathrm{A} \text { and } \mathrm{B} \\
& \text { Piece } \mathrm{N} 2=7 \mu \mathrm{m} \text { for } \mathrm{A} \text { and } 6 \mu \mathrm{m} \text { for B } \\
& \text { Piece } \mathrm{N} 3=4 \mu \mathrm{m} \text { for } \mathrm{A} \text { and } \mathrm{B} \\
& \text { Piece } \mathrm{N} 4=5 \mu \mathrm{m} \text { for } \mathrm{A} \text { and } 4 \mu \mathrm{m} \text { for B }
\end{aligned}
$$

b) Global shape tolerance for the pole profiles:

$$
\begin{aligned}
& \text { Piece } \mathrm{N} 1=14 \mu \mathrm{m} \\
& \text { Piece } \mathrm{N} 2=13 \mu \mathrm{m} \\
& \text { Piece } \mathrm{N} 3=10 \mu \mathrm{m} \\
& \text { Piece } \mathrm{N} 4=10 \mu \mathrm{m}
\end{aligned}
$$



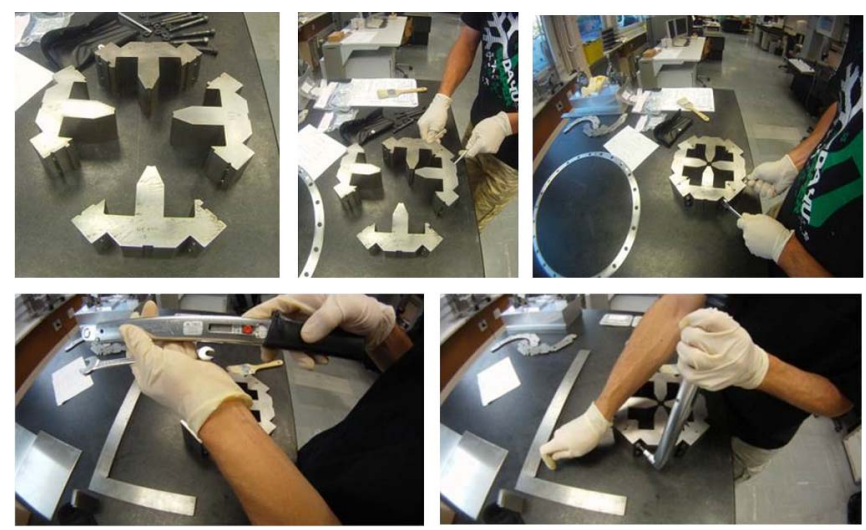

Fig. 6. Standard assembly procedure (from top left to bottom right) used for all the assembly tests: assembly with light torque-increase torque systematically—complete applying a measured torque of $10 \mathrm{~N} \cdot \mathrm{m}$.

c) Mean diameter of the pole cylindric part (nominal value: $\varnothing 16 \mathrm{~mm} \pm 5 \mu \mathrm{m})$ :

$$
\begin{aligned}
& \text { Piece } \mathrm{N} 1=\varnothing 16.016 \mathrm{~mm}( \pm 4.5 \mu \mathrm{m}) \\
& \text { Piece } \mathrm{N} 2=\varnothing 16.004 \mathrm{~mm}( \pm 2.5 \mu \mathrm{m}) \\
& \text { Piece N3 }=\varnothing 16.016 \mathrm{~mm}( \pm 2 \mu \mathrm{m}) \\
& \text { Piece N4 }=\varnothing 16.000 \mathrm{~mm}( \pm 2 \mu \mathrm{m}) .
\end{aligned}
$$

The shape tolerances obtained are globally very good. Only the pole profile region is slightly out of the $10 \mu \mathrm{m}$ target envelope. The good tolerances achieved for the mating surfaces and for the poles cylindrical parts have guaranteed the correctness of the assembly tests.

\section{The Yoke Assembly Tests}

The assembly test with the method a) "straight planes" appears to be very delicate (i.e. takes about 1 day of work); as a consequence this assembly method was tested only once. The methods b) "V-grooves with pins" and c) "assembly with steps" were repeated respectively 7 and 6 times to have more statistics to evaluate them.

The following procedure (shown in Fig. 6) was followed for all the assembly tests: put the pieces in contact and applying a minimum torque on the bolts-measurement-eventual adjustment-increasing the torque systematicallymeasurement—eventual adjustment—complete the assembly applying a measured torque of $10 \mathrm{~N} \cdot \mathrm{m}$.- final measurement.

\section{A. Results Obtained With the Assembly Method a) "Straight Planes"}

The individual measurement files for each quadrant were loaded and analyzed in CATIA 3D CAD software. In this way it was possible to determine "a priori" the best theoretical target values for each couple of quadrants assembly since they depend on the individual geometrical shapes.

During the assembly of the first two quadrants, when the computed theoretical best possible target value was achieved inside a limit of $5 \mu \mathrm{m}$, the assembly was considered good and then the pieces were tightened with the final torque. The next

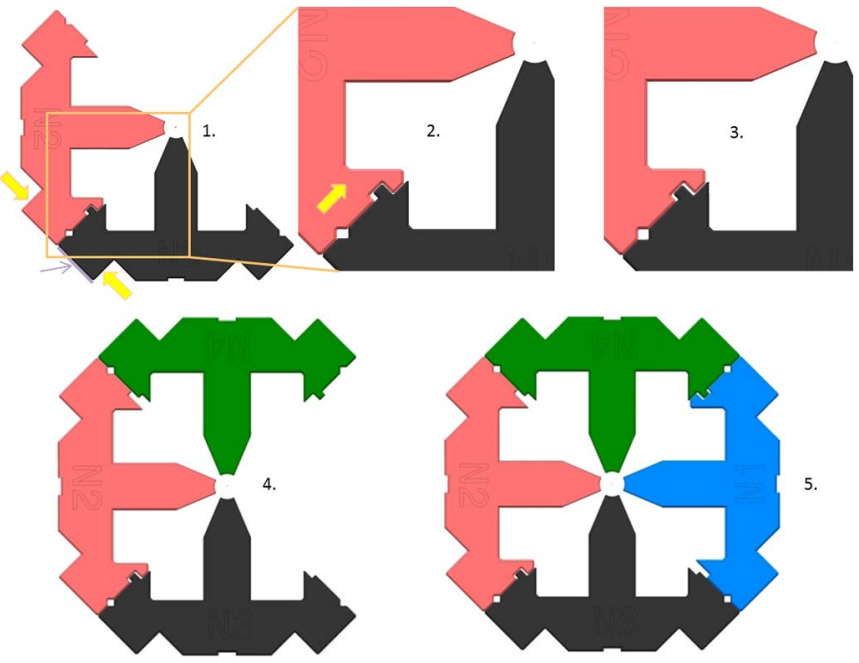

Fig. 7. Assembly procedure used for the test of the "straight planes" method. 1) Pre-assembly. 2) Adjustment (arrow) to $5 \mu \mathrm{m}$ tolerance of the pole centers. 3) Tighten with a torque of $10 \mathrm{~N} \cdot \mathrm{m}$. 4) Assembly of the 3rd quadrant. 5) Assembly of the last 4th quadrant.

TABLE I

Yoke Assembly Precision Obtained With the a) Method "Straight Planes"

\begin{tabular}{cccc}
\hline \hline Test n. & $\begin{array}{l}\text { Ø16 Cylindricity } \\
\text { error }[\mu \mathrm{m}]\end{array}$ & $\begin{array}{l}\text { Ø16 axis rectitude } \\
\text { error }[\mu \mathrm{m}]\end{array}$ & $\begin{array}{l}\text { Ø16 Mean } \\
\text { diameter }[\mathrm{mm}]\end{array}$ \\
\hline 1 & 74 & 1 & 16.002 \\
\hline
\end{tabular}

two quadrants were added in the same way. This procedure is schematized in Fig. 7.

The obtained assembly precision with method a) is reported in Table I.

\section{B. Results Obtained With the Assembly Method b) "V-Grooves With Pins"}

As mentioned, this assembly method was repeated $6(+1)$ times. It was the fastest assembly method. As for the previous method a), a preliminary analysis and matching of the single quadrant measurements with CATIA has permitted to define the nominal pin diameter to be used for the assembly (as shown in Fig. 8). The alignment precisions obtained with this method are reported in Table II.

In the seventh test, four identical pins of $4.000 \mathrm{~mm} \pm 0.5 \mu \mathrm{m}$ diameter were used. The aim of this last test was to check the result precision without using "individually adapted" pins and the test result is in fact very positive.

\section{Results Obtained With the Assembly Method c) "Assembly With Steps"}

This test was repeated six times. It had the advantage to be the most straightforward and easiest to be put in place since it does not need to work by steps as method a) nor with auxiliary pieces (pins) as method b). Obtained results are shown in Table III. This method shows a larger variance compared to the method b), so it can be considered the easiest assembly method between the 3 , but it is not the most precise. 


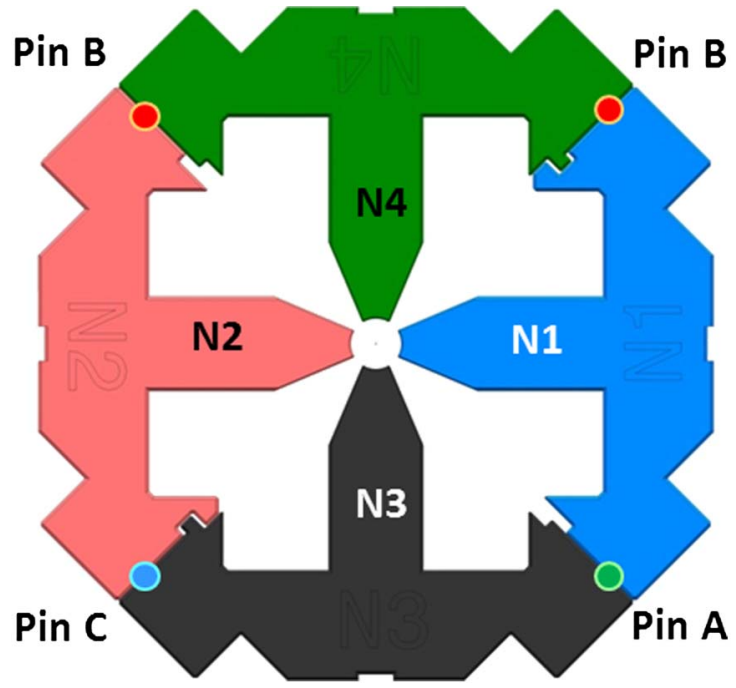

Fig. 8. Assembly procedure used for the "V-grooves with pins" assembly method. Nominal Pin A: $\varnothing 3.998 \mathrm{~mm} \pm 0.5 \mu \mathrm{m}$. Pins B: $\varnothing 4.000 \mathrm{~mm} \pm 0.5 \mu \mathrm{m}$. Pin C: $\varnothing 4.002 \mathrm{~mm} \pm 0.5 \mu \mathrm{m}$.

TABLE II

Quadrant Assembly Precision Obtained With the B) Method "V-Grooves With Pins"

\begin{tabular}{cccc}
\hline \hline Test $\mathrm{n}$. & $\begin{array}{l}\varnothing 16 \text { Cylindricity } \\
\text { error }[\mu \mathrm{m}]\end{array}$ & $\begin{array}{l}\text { ø16 axis rectitude } \\
\text { error }[\mu \mathrm{m}]\end{array}$ & $\begin{array}{l}\emptyset 16 \text { Mean } \\
\text { diameter }[\mathrm{mm}]\end{array}$ \\
\hline test 1 & 13 & 1 & 16.000 \\
test 2 & 14 & 0 & 16.001 \\
test 3 & 15 & 0 & 16.001 \\
test 4 & 14 & 0 & 16.001 \\
test 5 & 13 & 0 & 16.000 \\
test 6 & 16 & $\mathbf{0 . 2}$ & $\mathbf{1 6 . 0 0 0 5}$ \\
Mean value & $\mathbf{1 4 . 2}$ & 0 & 16.000 \\
test $7 *$ & 12 & & \\
\hline
\end{tabular}

* (with 4 pins of: $\varnothing 4,000 \mathrm{~mm} \pm 0.5 \mu \mathrm{m}$.)

TABLE III

Quadrant Assembly Precision ObTaIned With the C) Method "Assembly With Steps"

\begin{tabular}{cccc}
\hline \hline Test n. & $\begin{array}{l}\varnothing 16 \text { Cylindricity } \\
\text { error }[\mu \mathrm{m}]\end{array}$ & $\begin{array}{l}\varnothing 16 \text { axis rectitude } \\
\text { error }[\mu \mathrm{m}]\end{array}$ & $\begin{array}{l}\varnothing 16 \text { Mean } \\
\text { diameter }[\mathrm{mm}]\end{array}$ \\
\hline test 1 & 20 & 1 & 16.002 \\
test 2 & 18 & 1 & 16.002 \\
test 3 & 17 & 1 & 16.001 \\
test 4 & 23 & 1 & 16.001 \\
test 5 & 19 & 1 & 16.001 \\
test 6 & 54 & $\mathbf{0 . 8}$ & $\mathbf{1 6 . 0 0 1 3}$ \\
Mean value & 25.2 & & \\
\hline
\end{tabular}

\section{Results AnAlysis}

\section{A. Measurement Uncertainty and Limits of the Test}

The accuracy of the measuring machine used $(6 \mu \mathrm{m})$ should be taken into account evaluating the measurements. Despite this limitation, the results show a very good coherence and repeatability and no measurements appear to be outliers. This indicates that the test procedures were under control.

The length of the test pieces $(67 \mathrm{~mm})$ is short in comparison to the real quadrants (from 332 up to $1827 \mathrm{~mm}$ ). This makes it easier to obtain a higher assembly precision.

\section{B. Comparison of the Assembly Methods}

The assembly method b) "V-grooves with pins" is the most interesting of the three. It gives the best results in terms of overall assembly precision and the assembly time is short.

The assembly method c) "assembly with steps" is the simplest, very fast but the precision obtained is not as good as with method b).

The assembly method a) "straight planes" is the one needing the simplest (so cheapest) machining of the quadrants. This could be interesting for a series production (CLIC may need $4000 \mathrm{MBQ}$ units); however the assembly time is very long and the results are not very reproducible (as shown with a recent test on real magnets [5]).

\section{CONCLUSION}

Three methods for precise CLIC type compact quadrupole yoke assemblies were tested using very precise "ad-hoc" mockup components. Even if still preliminary, the results are positive and encouraging.

It was shown that for the precise assembly of the yokes, one of the three methods is the most interesting in terms of:

- Easy machining (low procurement price) of the quadrant mating surfaces,

- Time needed to perform a complete assembly of a yoke,

- Final geometrical precision obtained.

A future test program will be needed to optimize the geometry for the identified best method (the "V-grooves" geometry) and to test it on a real quadrupole assembly. We have already procured the Type1 quadrupoles components (quadrants and coils) so this program could be completed in a relatively short time. Magnetic measurements will be part of the final tests.

\section{REFERENCES}

[1] CLIC Conceptual Design Report, CERN, Meyrin, Switzerland. [Online]. Available: http://clic-study.org/accelerator/CLIC-ConceptDesignRep.php

[2] N. Marks, "Conventional magnets for accelerators," in Proc. Lectures CERN Accelerator School (CAS), Zakopane, Poland, Oct. 2006.

[3] "Magnets," Proc. CERN Accelerator School (CAS), Bruges, Belgium, Jun. 16-25, 2009.

[4] A. Vorozhtsov and M. Modena, "Design and manufacture of a main beam quadrupole model for CLIC," IEEE Trans. Appl. Supercond., vol. 22, no. 3, p. 4002404, Jun. 2012.

[5] M. Modena, A. Bartalesi, J. Garcia Perez, R. Leuxe, G. Perrin-Bonnet, C. Petrone, M. Struik, and A. Vorozhtsov, "Performances of the main beam quadrupole type 1 prototypes for CLIC," presented at the 23rd Int. Conf. Magnet Technol., Boston, MA, USA, Jul. 2013, unpublished. 